\title{
Case Report Hypertriglyceridemia Induced Pancreatitis (Chylomicronemia
Syndrome) Treated with Supportive Care
}

\author{
Emin Uysal, ${ }^{1}$ Yahya Ayhan Acar, ${ }^{2}$ Emel Gökmen, ${ }^{3}$ Ahmet Kutur, ${ }^{1}$ and Hatice Doğan' \\ ${ }^{1}$ Department of Emergency Medicine, Bagcilar Training and Research Hospital, Bağcllar, 34200 Istanbul, Turkey \\ ${ }^{2}$ Department of Emergency Medicine, Etimesgut Military Hospital, Etimesgut, 06797 Ankara, Turkey \\ ${ }^{3}$ Department of Internal Medicine, Bagcilar Training and Research Hospital, Bağcilar, 34200 Istanbul, Turkey
}

Correspondence should be addressed to Yahya Ayhan Acar; yahya_acar@yahoo.com

Received 22 May 2014; Revised 9 November 2014; Accepted 9 November 2014; Published 23 November 2014

Academic Editor: Moritoki Egi

Copyright (c) 2014 Emin Uysal et al. This is an open access article distributed under the Creative Commons Attribution License, which permits unrestricted use, distribution, and reproduction in any medium, provided the original work is properly cited.

Hypertriglyceridemia is a rare cause of pancreatitis. In treatment pancreatic rest, lifestyle changes, medications (fibrates, n-3 polyunsaturated fatty acids, and nicotinic acid) are essential. Many experimental treatment modalities have been reported as insulin and heparin infusion and plasmapheresis. In this study we present the hypertriglyceridemia-induced pancreatitis treated with supportive care.

\section{Introduction}

Hypertriglyceridemia-induced pancreatitis (HTIP) is a rare but well known clinical condition. Triglyceride (TG) level above $1000 \mathrm{mg} / \mathrm{dL}$ is defined as chylomicronemia and chylomicronemia syndrome (CS) is the condition being TG > $1000 \mathrm{mg} / \mathrm{dL}$ and additionally one of eruptive xantomas, lipemia retinalis, or abdominal pain/pancreatitis [1]. CS is also HTIP and it was defined for the practical approach to management [1]. The exact mechanism of hypertriglyceridemia (HTG) in pancreatitis could not be identified clearly [2] and many treatment modalities were reported. In this study, we reported a HTIP (chylomicronemia syndrome) case treated with supportive care.

\section{Case Presentation}

A 42-year-old man was admitted to emergency department with a $1 \mathrm{~h}$ history of abdominal pain, nausea, and nonbilious vomiting. He had a past medical history of diabetes mellitus, hypertension, hypothyroidism, and hypertriglyceridemia. The patient reported taking levothyroxine $(50 \mathrm{mg}$ oral once a day), amlodipine ( $5 \mathrm{mg}$ oral once a day), insulin glargine (20 U subcutaneous once a day), metformin $(1000 \mathrm{mg}$ oral three times a day), and rosuvastatin ( $20 \mathrm{mg}$ oral once a day).
He ran out of fenofibrate the month before. The patient denied any fever, jaundice, or alcohol consumption. The physical examination showed a temperature of $36.8^{\circ} \mathrm{C}$, blood pressure of $130 / 80 \mathrm{mmHg}$, respiratory rate of $18 / \mathrm{min}$, and pulse rate of $110 / \mathrm{min}$. The abdomen examination was significant for rebound and tenderness in epigastric region. Any other abnormality was not detected in abdominal, respiratory, cardiovascular, and neurologic examination.

Relevant laboratory results at the time of admission were as follows. White blood cell count was $13.740 / \mathrm{mm}^{3}$ (ref: 3.29.7), hemoglobin was $17.5 \mathrm{~g} / \mathrm{dL}$ (ref: 13-17.2), and C-reactive protein was $1.4 \mathrm{mg} / \mathrm{dL}$ (ref: $0-5$ ). Blood glucose level was $417 \mathrm{mg} / \mathrm{dL}$ (ref: 74-106), urine ketones were $(+)$ and in arterial blood gas analyze $\mathrm{pH}$ was 7.44, pO2: 92.6, pCO2: 34.8, and SaO2: $99.1 \%$. While serum amylase was normal (75 U/L, ref: 30-118), lipase level was elevated (2914 U/L, ref: 6-51). Transaminase levels were also elevated (ALT: $157 \mathrm{U} / \mathrm{L}$, ref: 1-40; AST: 17, ref: 1-40). Measured serum sodium was $116 \mathrm{mmol} / \mathrm{L}$ (ref: 132-136), and corrected serum sodium was $124 \mathrm{mmol} / \mathrm{L}$ [3]. Chest X-ray and abdominal X-ray were normal. USG of the abdomen showed grade 3 hepatosteatosis but any abnormality in biliary or pancreatic regions was not reported. Abdominal computed tomography (CT) confirmed pancreatic edema consistent with acute pancreatitis (Figure 1). 


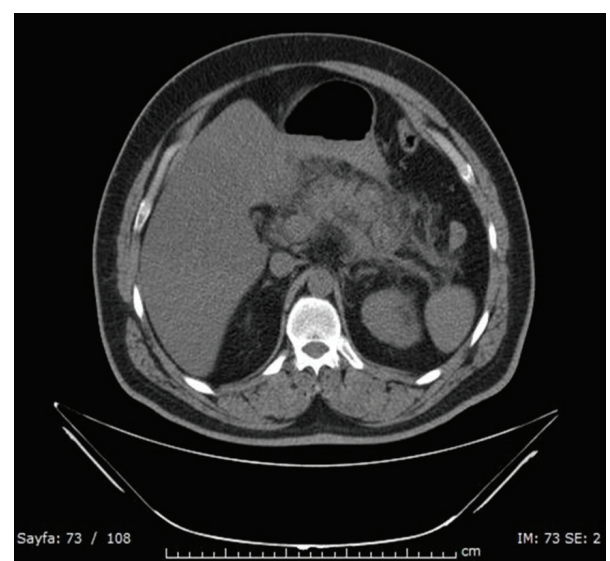

FIGURE 1: Computed tomography of abdomen showed edematous characteristics in peripancreatic region.

Patient was hospitalized in Internal Medicine Clinic with the diagnosis of nonbiliary pancreatitis. The patient had uncontrolled diabetes mellitus and hyperlipidemia (HbAlc: 7.3\%, ref: 4-6; glucose: $352 \mathrm{mg} / \mathrm{dL}$, ref: 74-106; cholesterol: $800 \mathrm{mg} / \mathrm{dL}$, ref: 1-200; triglyceride: $3454 \mathrm{mg} / \mathrm{dL}$, ref: 0-200) and diagnosis was directed to HTIP. The serum was lipemic on gross examination (Figure 2). The patient was kept nil per mouth, intravenous fluid therapy, and oral medical therapy (including fenofibrate) started consistent with previous therapy. During the hospital stay, his abdominal pain, triglyceride, and pancreatic enzyme levels were improved.

He had no abdominal pain and was discharged from hospital on day 9 with a triglyceride level of $1669 \mathrm{mg} / \mathrm{dL}$, cholesterol level of $435 \mathrm{mg} / \mathrm{dL}$, amylase level of $40 \mathrm{U} / \mathrm{L}$, lipase level of $91 \mathrm{U} / \mathrm{L}$, and sodium level of $136 \mathrm{mg} / \mathrm{dL}$. HTIP did not recur in six-month follow-up.

\section{Discussion}

Pancreatitis is a clinical condition characterized with broad inflammation in pancreas. Although biliary stones and alcohol consumption are the major etiologic group of pancreatitis, HTG is a rare but well-known cause of pancreatitis in up to $10 \%$ of all cases [4]. Causes of HTIP can be divided into two main groups: (1) genetic factors: familial combined hyperlipidemia, familial hypertriglyceridemia, familial dysbetalipoproteinemia, and familial chylomicronemia syndrome and (2) secondary factors: untreated/poorly controlled diabetes mellitus (DM), alcohol abuse, pregnancy, and medications [5]. Possible mechanism of pancreatitis in hypertriglyceridemic patients is the damage of asinar cells and microvascular membrane due to excessive free fatty acid and lysolecithin formation in pancreatic bed from lipoprotein substrates [6].

Initial treatment of HTIP includes pancreas rest (by limiting oral intake, aggressive intravenous hydration, and analgesia) [5]. For further treatment of HTIP, plasmapheresis [7-9], heparin infusion [10-16], and subcutaneous heparin [17] were reported, but still they are considered as experimental treatment modalities in HTIP [5]. Apheresis has been recommended as category III (optimum role of

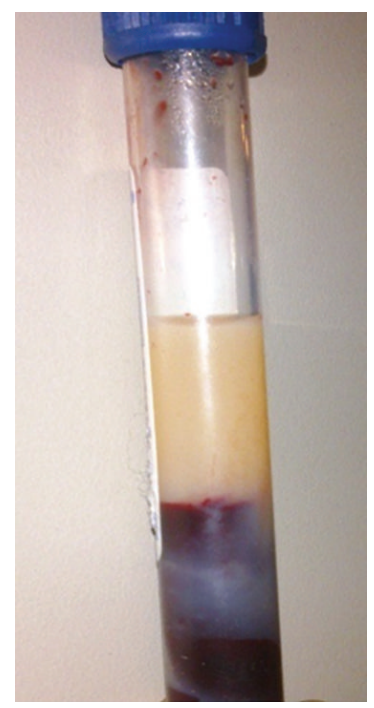

FIgURE 2: Lipemic serum of patient.

apheresis therapy is not established; individualized decision is necessary) and grade-2C (weak recommendation, lowquality, or very low-quality evidence) for hypertriglyceridemic pancreatitis by American Society for Apheresis [18]. European Atherosclerosis Society (EAS) mentioned apheresis to be able to lower TG levels rapidly in acute settings rather than a standard therapy [19]. Heparin has been reported as controversial because of the hemorrhage into the pancreatic bed in the setting of pancreatitis [18]. Anderson et al. reported standard therapy of intravenous fluids, nil by mouth and supportive care alone was equivalent to the use of dextrose and insulin in resolution of HTG in pancreatitis [20]. Our patient was treated with supportive care, but previous insulin glargine therapy was continued for DM. We report a HTIP case treated with supportive care without any administration of heparin or apheresis [21].

It was reported that TG levels below $1772 \mathrm{mg} / \mathrm{dL}(20 \mathrm{nM})$ are unlikely to be the primary cause of pancreatitis and most of these patients have also uncontrolled diabetes mellitus as secondary cause [2]. However, TG levels $>1000 \mathrm{mg} / \mathrm{dL}$ are considered as a causative reason for HTIP recurrence; this threshold is still arbitrary [4]. Hospitalization and nothing by mouth were recommended for patients whose TG levels $>500 \mathrm{mg} / \mathrm{dL}$ with abdominal pain [1]. Our patient's TG level was $3454 \mathrm{mg} / \mathrm{dL}$ in admission and $1669 \mathrm{mg} / \mathrm{dL}$ in discharge. We discharged the patient because of improving clinical condition, lack of abdominal pain, decreasing trend in TG levels, good compliance to treatment, and diet.

Serum amylase concentration may be in normal ranges in HTIP [11]. Our patient's amylase levels were also in normal ranges. Mechanism of normoamylasemia is believed to be the inadequacy of calorimetric method and serial dilutions of the sample can reduce interference of light transmission by hyperlipidemic serum [22, 23]. Our patient had normal amylase levels and high lipase levels. Lipase levels may be 
more sensitive in pancreatitis diagnosis or minimally affected from HTG state.

Clinical suspicion of pancreatitis should be kept in mind even with normal amylase levels especially in the presence of hypertriglyceridemia. Supportive care may be sufficient in therapy. Controlled clinical trials are essential for improving therapy modalities in HTIP.

\section{Prior Publication}

This article has not been published or submitted for publication elsewhere, in whole or in part, before submission to the Case Reports in Critical Care.

\section{Consent}

The authors declare that they have provided written informed consent from the described patient for the case report to be published.

\section{Conflict of Interests}

The authors declare that there is no conflict of interests regarding the publication of this paper.

\section{References}

[1] D. A. Leaf, "Chylomicronemia and the chylomicronemia syndrome: a practical approach to management," The American Journal of Medicine, vol. 121, no. 1, pp. 10-12, 2008.

[2] S. Sandhu, A. Al-Sarraf, C. Taraboanta, J. Frohlich, and G. A. Francis, "Incidence of pancreatitis, secondary causes, and treatment of patients referred to a specialty lipid clinic with severe hypertriglyceridemia: a retrospective cohort study," Lipids in Health and Disease, vol. 10, article 157, 2011.

[3] T. A. Hillier, R. D. Abbott, and E. J. Barrett, "Hyponatremia: evaluating the correction factor for hyperglycemia," American Journal of Medicine, vol. 106, no. 4, pp. 399-403, 1999.

[4] P. Valdivielso, A. Ramirez-Bueno, and N. Ewald, "Current knowledge of hypertriglyceridemic pancreatitis," European Journal of Internal Medicine, vol. 25, no. 8, pp. 689-694, 2014.

[5] J. Scherer, V. P. Singh, C. S. Pitchumoni, and D. Yadav, "Issues in hypertriglyceridemic pancreatitis: an update," Journal of Clinical Gastroenterology, vol. 48, no. 3, pp. 195-203, 2014.

[6] W. Kimura and J. Mössner, "Role of hypertriglyceridemia in the pathogenesis of experimental acute pancreatitis in rats," The International Journal of Pancreatology, vol. 20, no. 3, pp. 177-184, 1996.

[7] A. M. Cahalane, M. J. Smith, J. Ryan, and D. Maguire, "Acute pancreatitis secondary to gestational hypertriglyceridaemia," Case Reports in Medicine, vol. 2012, Article ID 627890, 5 pages, 2012.

[8] J.-P. Routy, G. H. R. Smith, D. W. Blank, and B. M. Gilfix, "Plasmapheresis in the treatment of an acute pancreatitis due to protease inhibitor-induced hypertriglyceridemia," Journal of Clinical Apheresis, vol. 16, no. 3, pp. 157-159, 2001.

[9] S. B. Iskandar and K. E. Olive, "Plasmapheresis as an adjuvant therapy for hypertriglyceridemia-induced pancreatitis," The American Journal of the Medical Sciences, vol. 328, no. 5, pp. 290-294, 2004.
[10] D. Jain and J. Zimmerschied, "Heparin and insulin for hypertriglyceridemia-induced pancreatitis: case report," The Scientific World Journal, vol. 9, pp. 1230-1232, 2009.

[11] P. Sharma, S. Lim, D. James, R. T. Orchard, M. Horne, and C. A. Seymour, "Pancreatitis may occur with a normal amylase concentration in hypertriglyceridaemia," British Medical Journal, vol. 313, no. 7067, p. 1265, 1996.

[12] H. Alagözlü, M. Cindoruk, T. Karakan, and S. Ünal, "Heparin and insulin in the treatment of hypertriglyceridemia-induced severe acute pancreatitis," Digestive Diseases and Sciences, vol. 51, no. 5, pp. 931-933, 2006.

[13] M. R. Aryal, N. R. Mainali, S. Gupta, and M. Singla, "Acute pancreatitis owing to very high triglyceride levels treated with insulin and heparin infusion," BMJ Case Reports, 2013.

[14] P. Jain, R. R. Rai, H. Udawat, S. Nijhawan, and A. Mathur, "Insulin and heparin in treatment of hypertriglyceridemiainduced pancreatitis," World Journal of Gastroenterology, vol. 13, no. 18, pp. 2642-2643, 2007.

[15] A. Monga, A. Arora, R. P. S. Makkar, and A. K. Gupta, "Hypertriglyceridemia-induced acute pancreatitis-treatment with heparin and insulin," Indian Journal of Gastroenterology, vol. 22, no. 3, pp. 102-103, 2003.

[16] A. D. Patel, "Hypertriglyceridemia-induced acute pancreatitis treatment with insutin and heparin," Indian Journal of Endocrinology and Metabolism, vol. 16, no. 4, pp. 671-672, 2012.

[17] U. Cheema and N. Noman, "Subcutaneous heparin for treatment of hypertriglyceridemia-induced pancreatitis," American Journal of Health-System Pharmacy, vol. 69, no. 14, pp. 1187-1188, 2012.

[18] J. Schwartz, J. L. Winters, A. Padmanabhan et al., "Guidelines on the use of therapeutic apheresis in clinical practice - Evidencebased approach from the writing committee of the american society for apheresis: the sixth special issue," Journal of Clinical Apheresis, vol. 28, no. 3, pp. 145-284, 2013.

[19] P. European Association for Cardiovascular and Rehabilitation, Z. Reiner, A. L. Catapano et al., "ESC/EAS Guidelines for the management of dyslipidaemias: the Task Force for the management of dyslipidaemias of the European Society of Cardiology (ESC) and the European Atherosclerosis Society (EAS)," European Heart Journal, vol. 32, no. 14, pp. 1769-1818, 2011.

[20] F. Anderson, S. Z. Mbatha, and S. R. Thomson, "The early management of pancreatitis associated with hypertriglyceridaemia," South African Journal of Surgery, vol. 49, no. 2, pp. 82-84, 2011.

[21] J. H. Bae, S. H. Baek, H. S. Choi et al., "Acute pancreatitis due to hypertriglyceridemia: report of 2 cases," The Korean Journal of Gastroenterology, vol. 46, no. 6, pp. 475-480, 2005.

[22] D. Yadav, S. Nair, E. P. Norkus, and C. S. Pitchumoni, "Nonspecific hyperamylasemia and hyperlipasemia in diabetic ketoacidosis: incidence and correlation with biochemical abnormalities," The American Journal of Gastroenterology, vol. 95, no. 11, pp. 3123-3128, 2000.

[23] L. A. Donaldson and W. McIntosh, "Letter: hypertriglyceridaemia and abdominal pain," British Medical Journal, vol. 1, no. 6013, p. $833,1976$. 


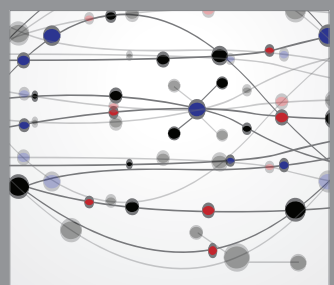

The Scientific World Journal
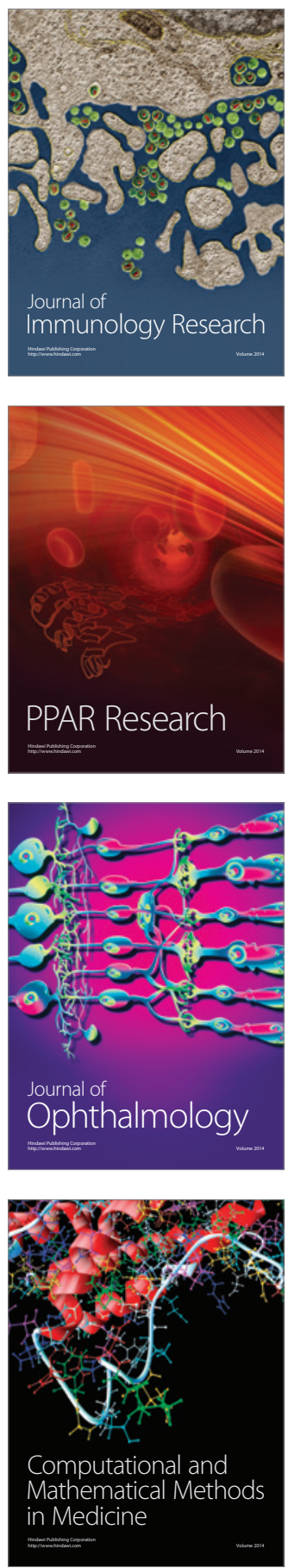

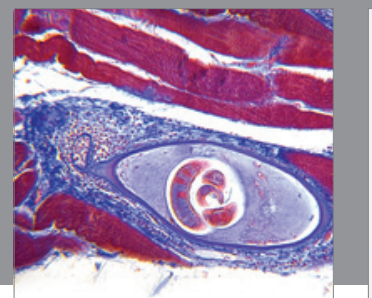

Gastroenterology

Research and Practice
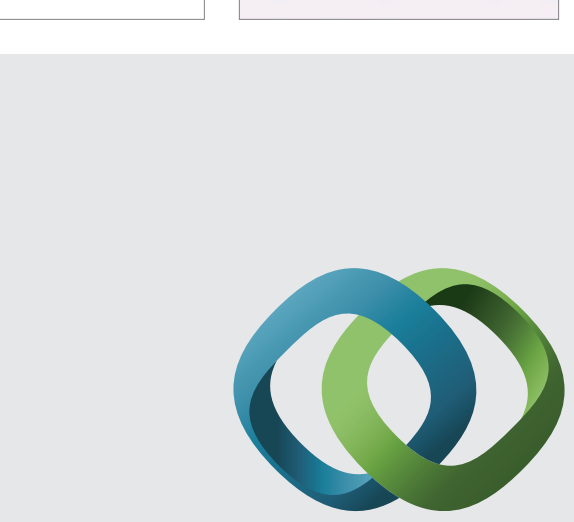

\section{Hindawi}

Submit your manuscripts at

http://www.hindawi.com
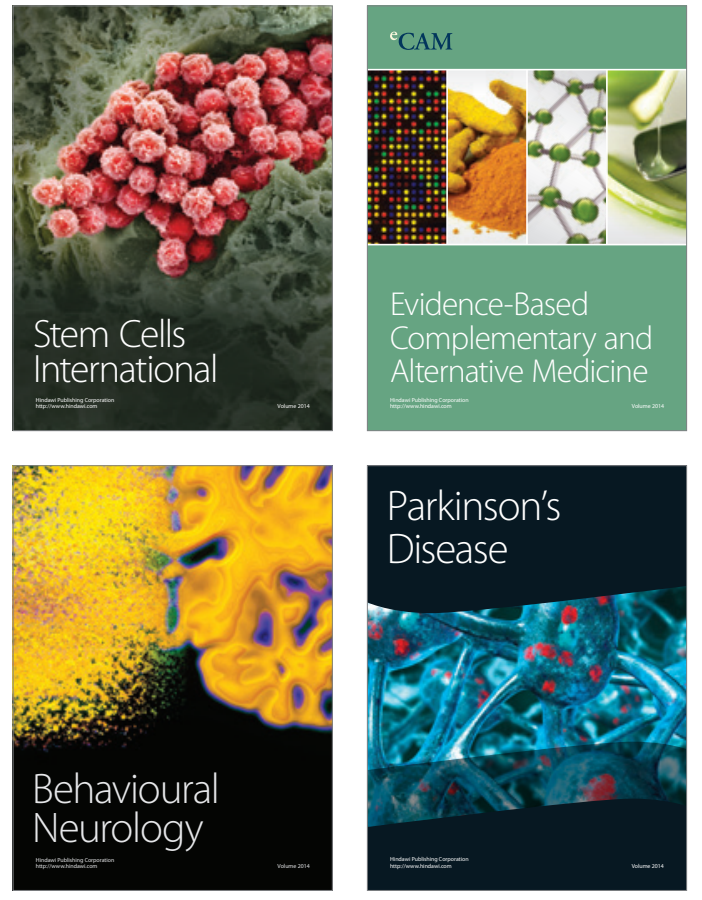
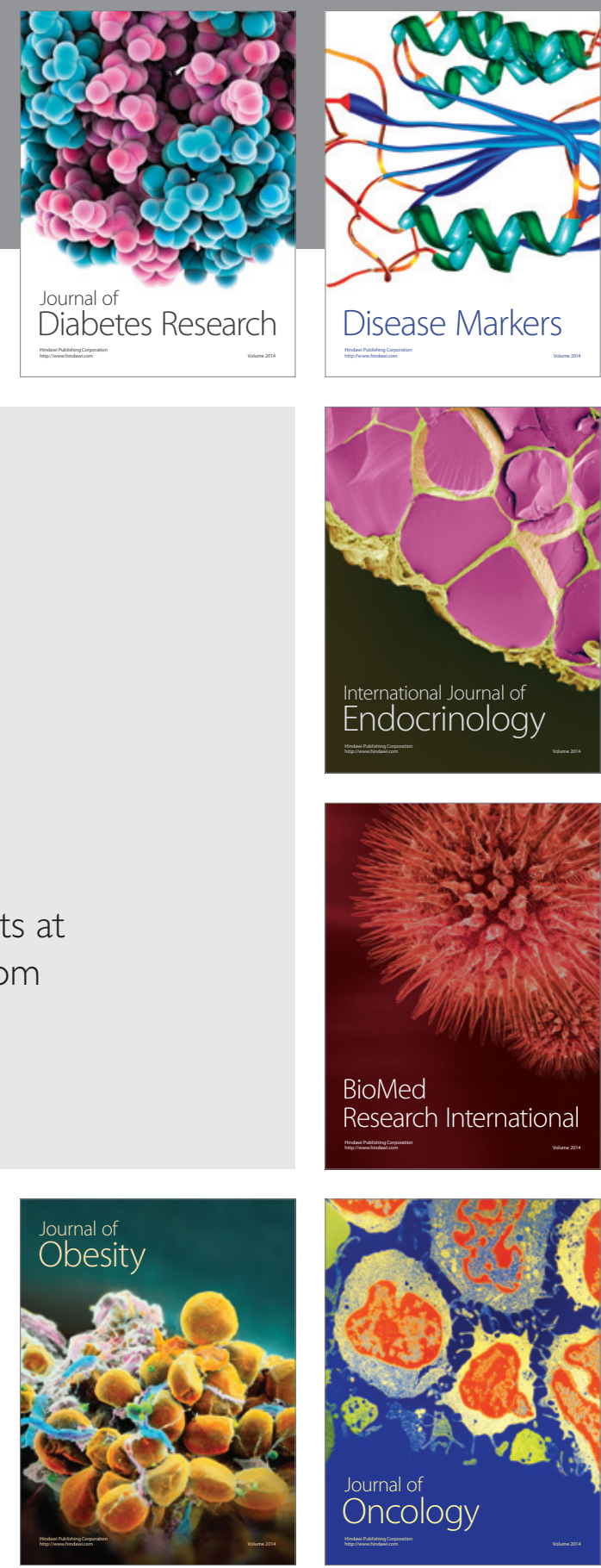

Disease Markers
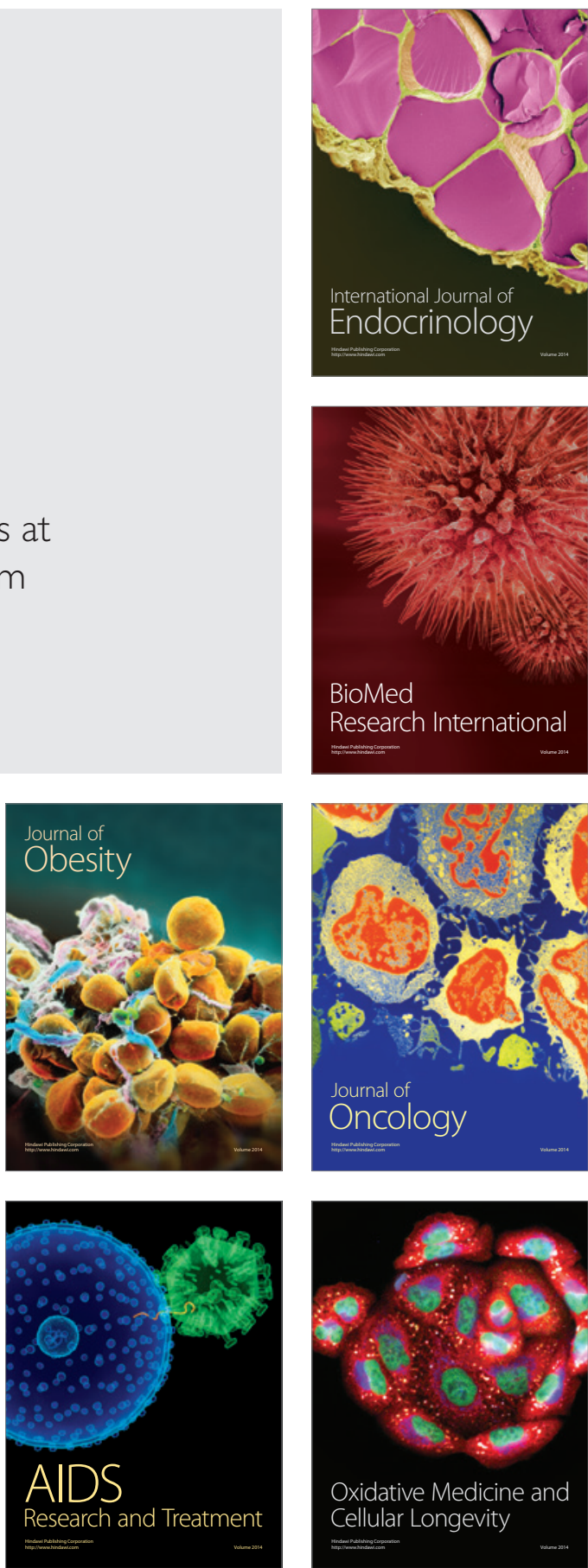